\title{
Assessment of pesticides residues contents in the vegetables cultivated in urban area of Lome (southern Togo) and their risks on public health and the environment, Togo
}

\author{
Housséni AHOUDI ${ }^{1 *}$, Kissao GNANDI ${ }^{1}$, Gnon TANOUAYI ${ }^{1}$, Kamilou OURO-SAMA $^{1}$, \\ Jean-Christophe YORKE ${ }^{2}$, E. Edmond CREPPY ${ }^{3}$ and Christian $\mathrm{MOESCH}^{2}$ \\ ${ }^{1}$ Faculté des Sciences, Département des géosciences et environnement, Université de Lomé, BP : 1515 \\ Lomé-Togo. \\ ${ }^{2}$ Laboratoire de Pharmacologie et Toxicologie, Centre Hospitalier Universitaire de Limoges, France. \\ ${ }^{3}$ Laboratoire de Toxicologie et Hygiène Appliquée, Faculté de Pharmacie, Université de Bordeaux, 146 rue \\ Léo Saignat, France. \\ *Corresponding author; E-mail: ahoudih@yahoo.fr; Tél: +22891688687
}

\section{ACKNOWLEDGMENTS}

This work was supported by the French government's cooperation and cultural action grant (SCAC) in Togo. Grant Number 891761B, 2017.

\begin{abstract}
The objective of this study was the evaluation of the health risks of the pesticides use and their bioaccumulation by the vegetables grown in Lomé gardens. Pesticide residues levels were assessed in vegetable samples collected in Lomé areas by Gaz chromatography - mass spectrometry or liquid chromatography - mass spectrometry in order to know their concentrations. Data obtained were used for estimating the potential health risks associated with the exposures to these pesticides. The results showed that all of the samples contain pesticide residues with high levels of Dithiocarbamates $(7.79 \mathrm{ppm})$ in carrots, Chlorpyriphos ethyl $(0.445 \mathrm{ppm})$ in spinach, cucumbers $(0.239 \mathrm{ppm})$, peppers $(0.032 \mathrm{ppm})$, and turnips. Levels above the maximum residue limits (MRLs) of chlorothalonil, and carbendazime were found in peppers, prothioconazole and pendimethalin in turnips, cypermethrin in pepper $(0.254 \mathrm{ppm})$ and in eggplant $(0.037$ ppm). The pepper has concentrated 5 residues, leek and turnip 4 residues each other, African eggplant 3, lettuce 2 residues and spinach 2 residues. The health risks indices show that the detected pesticides could not be considered as a serious public health problem in the studied conditions, but there is the need to increase their monitoring to reduce their misuse on the vegetables.
\end{abstract}

(C) 2018 International Formulae Group. All rights reserved.

Keywords: Pesticides residues, vegetables, consumers, health risks indices, Lome-togo.

\section{INTRODUCTION}

Number of agriculture products, especially vegetables, are an important component of the human diet as these are sources of vitamins and minerals that are known for boosting the immune system and body development. (Iqbal et al., 2009). Health professionals as well as nutritionists 
keep encouraging people living on fruits and vegetables to avoid killer diseases such as cancer and cardiovascular diseases. While others think the gain associated with the consumption of fruits and vegetables, there is growing concern on their cultivation with agrochemicals, fertilisers, and pesticides (Donkor et al., 2016).

Pesticides are mostly chemical substances, which are commonly used in modern agriculture practices to protect the crops from different pests and diseases (Guler et al., 2010; Minfal, 2004). They are known to improve agriculture yield considerably leading to an increase in its application over the years (Donkor et al., 2016). However the blind use of these pesticides on vegetables is one of the main challenges on environmental pollution and public health. In the republic of Benin, Bgaguidi, et al. (2001), have found pesticide residues in water and sediments of the river Agbado testifying environmental pollution by these substances. These pesticides are used early, and most of market gardeners are illiterate or have low levels of education and poor knowledge of recommended doses. Synthetic pesticides such as insecticides, herbicides, and fungicides have been popular with farmers, because of their widespread availability, simplicity in application, efficacy and economic returns (Khizar et al., 2010; Mahob et al. 2014).

The consequence is the supply and use of all kinds of pesticides, ignoring the health risks to which they are exposed daily and increasing the amount of residues in vegetables (Adjrah et al., 2013). In addition to being neurotoxic, these compounds are profoundly injurious to the immune and endocrine systems as well (HSDB, 2018a; Steeve et al. 2013; Sánchez-Guerra et al., 2013). Many pesticides that are dangerous to humans and other organisms are increasingly used in market gardening to protect crops and increase yields (Yazgan et al. 2005; Wilson \& Tisdell, 2001). The organochlorine pesticides are known to induce changes in reproductive development, function or behaviour in wildlife and are prohibited in developed countries but their usage still frequent in
Africa as it was demonstrated by Biego et al. (2009) in the Ivory Coast. Apart from accidental or deliberate acute poisoning, repeated exposure to these products or the consumption of food and vegetables contaminated by their residues, have been shown to cause a variety of human health disorders such as endocrine disruptions, disorder of the immune system, the emergence of certain types of cancer, reproductive disorders (Jean-Pierre and Pascal, 2009). In Lomé, market gardening in urban areas contributes to food security and is an important source of employment and income. However, the excessive use of synthetic chemical pesticides and chemical fertilisers to increase yields is a cause for concern, as many studies have shown it. For example, Kanda et al. (2013) studies on the application of pesticides and chemical fertilisers in market gardening in Lomé have shown a lack of training and control on the use of these chemicals and the health risks of the populations. Similarly, the work of Adjrah et al. (2013) showed the randomly and the hazardous use of plant protection products on the southern coast of Togo. This is demonstrated by the work of Kokou et al. (2014), which identified the development of an informal trade in plant protection products in southern Togo, along the Togo-Ghana border, with 193 trademarks listed, of which only 35 are licensed for Food crops. As a result, the level of pesticide residues in or on vegetables at the moment of harvest is higher than the level permitted by regulations. As known Lomé is one of the important trade centres in the West African region, it is necessary to assess the pesticides residue levels in the vegetables for the trading at national or international level and establish a database for pesticide residues. All these studies show a need to quantify the residues of these pesticides in the vegetables and to determine their pollution levels, in order to protect consumers and the environment. To assess the accumulation of pesticide residues in vegetables, 14 samples in triplicates were taken randomly in the market gardens of the city of Lomé and their pesticide residue levels 
determined in the Departement of Pharmacology, and Toxicology of the University hospital of Limoges in France. The objective of this study was to assess pesticides residue levels in the vegetables commonly consumed in Lomé, and evaluate their health risks according to estimated exposure, in order to protect the consumers and the environment.

\section{MATERIALS AND METHODS}

The selection of areas was based on the higher pesticide consumption and extensive agriculture production of numerous vegetables. Before taking the vegetable samples from the areas, interviews were conducted with reference to the pesticides use to get knowledge about the types and number of pesticides applied, the period of application and harvest, the kinds of vegetables grown and the gardener's exposure to pesticides, their age, sex and clinical history.

\section{Sampling Zone}

The sampling zone is Lomé, the capital of Togo which is the study area is located on the shoreline between $1^{\circ} 14^{\prime} 0^{\prime \prime}$ and $1^{\circ} 24^{\prime} 0^{\prime \prime}$ east longitude, and $6^{\circ} 7^{\prime} 12$ "and $6^{\circ} 12^{\prime} 0^{\prime \prime}$ north latitude. This area (figure 1) located between the lagoon system and the Atlantic Ocean is a coastline parallel to the coast line from the Ghana's border to Baguida. It enjoys a sub-Equatorial Guinean climate with a bimodal regime. The average annual rainfall is $860 \mathrm{~mm} /$ year and the relative humidity is 80 $90 \%$. The mean evapotranspiration is 1540 $\mathrm{mm} /$ year and the average temperature range from 26 to $33{ }^{\circ} \mathrm{C}$. The soils developed on the coastal sands are poor in organic matter and minerals, they are permeable and their water reserve is low.

\section{Sample collection and preparation}

A total of 14 vegetable samples in triplicate (Table 1) were randomly collected at different points in Lomé market garden areas. During sampling, dead or vegetable parts along the aisles, were immediately disposed of and samples were packaged in a cooler before being transported to the University's Waste Treatment and Recovery Laboratory (GTVD) of Lomé. They were then washed with tap water to simulate their consumption before being packed in aluminium foil and stored in a freezer at a temperature below $4{ }^{\circ} \mathrm{C}$. Finally, they were transferred to the Departement of Pharmacology, Toxicology of the University hospital of Limoges for the analysis of pesticides. The laboratory is accredited by the French Accreditation Committee International Organisation for Standardisation (COFRAC ISO 17025) for the dosages of these food contaminants.

\section{Instrumentation}

For the pesticide determination, the analyses were carried out by several analytical systems. LC-MS/MS screening system by AB Sciex 5500 triple quadrupole mass spectrometer equipped triple quad equipped with an automatic injector model SIL 20AC, 2 pumps for liquid chromatography model LC 20AD, and a column oven Model CTO- 20A, is used. The separation of the pesticides is carried out by a liquid chromatography system using a Shimadzu high-pressure binary mixture equipped with a $100 \mathrm{~m}$ long Restek reverse phase chromatographic column and $2.1 \mathrm{~mm}$ internal diameter filled with particles of $3 \mu \mathrm{m}$ in diameter. Detection and quantification were performed by the quadrupole triple mass spectrometer in MRM (Multiple Reaction Monitoring) mode with a positive-to-negative polarity alternation. Screening by GC-MS/MS by Agilent 7000C GC-TQ MSD 5973 quadrupole mass spectrometer in split mode $(1 / 10)$, coupled to Hewlett-Packard 7890B GC gas chromatograph and the separation of pesticides is done by a chromatographic column of 5-MS Agilent $30 \mathrm{~m}$ length, 0.25 $\mathrm{mm}$ internal diameter with a polar film of 0.25 microns. For the determination of dithiocarbamates, the Headspace - Gas Chromatography - Mass spectrometry (HSGC-MS) system is used. It consists of a Hewlett-Packard HP 5973 MSD single quadrupole mass spectrometer equipped with Perkin Elmer HS 40XL headspace injector coupled to a gas chromatograph GC HP 6890 
by a heated transfer line. The separation of the pesticides is carried out by a Restek RTX chromatographic column of 60-metre length, and $0.32 \mathrm{~mm}$ of internal diameter, with a film of $5 \mu \mathrm{m}$.

\section{Instrumental conditions}

The operating conditions for LCMS/MS were as follows: The injection flow rate was $400 \mu \mathrm{L} / \mathrm{min}$. Detection and quantification are performed by the quadrupole triple mass spectrometer in MRM (Multiple Reaction Monitoring) mode. The whole analysis time for the system was 22 $\mathrm{min}$, and the time for the equilibration of the system was put $0.5 \mathrm{~min}$.

For GC-MS/MS, confirmation the working conditions were as follows: The temperature for injector port was $250{ }^{\circ} \mathrm{C}$, volume of injection was $2 \mu \mathrm{l}$ in splitless manner (1/10), helium (99.99 \%) used as carrier gas at $2 \mu \mathrm{l} / \mathrm{min}$ flow rate. For column the temperature program was the same as in GC-MS/MS. The Mass spectrometry was run in electrons impact ionisation manner (I.E = $70 \mathrm{eV}$ ) scanning as from $\mathrm{m} / \mathrm{z} 50$ to 550 at 4.4 scan/s. Temperatures of ionisation source and quadrupole were adjusted from $60{ }^{\circ} \mathrm{C}$ to 310 ${ }^{\circ} \mathrm{C}$. For the headspace - mass spectrometry analytical system, the samples are introduced into an enclosure thermostated at $90{ }^{\circ} \mathrm{C}$ for 40 min. Transfer line temperature was $50{ }^{\circ} \mathrm{C}$ and ion energy for electron impact (EI) was always $70 \mathrm{eV}$. The ion source and quadrupole temperatures were 230 and $150{ }^{\circ} \mathrm{C}$, respectively. Mass spectrometry was run in electrons impact ionisation manner.

\section{Extraction}

All reagents and chemicals were of analytical grade and were used as received. Extraction of pesticide residues from the vegetable samples was done according to the analytical method used in the laboratories. Standards of the pesticides were obtained from Aldrich Sigma (Germany), always with purity higher than $99 \%$.

About 205 residues of pesticides were determined by screening in all samples. Each vegetable sample was thoroughly chopped using a laboratory knife and blended. After grounding, a total of $10 \mathrm{~g}$ was then taken from the composite sample and placed in a $50 \mathrm{ml}$ falcon tube. $10 \mathrm{ml}$ of acetonitrile and a mixture of salts of QUECHER mix1 (1 g $\mathrm{NaCl}, 4 \mathrm{~g} \mathrm{MgSO} 4,1 \mathrm{~g}$ trisodium citrate, $0.5 \mathrm{~g}$ disodium citrate) were added and the mash was stirred (Koesukwiwat et al. 2010). After centrifugation the supernatant was removed for analysis. For LC-MS/MS analysis, the supernatant was diluted half by a buffer. For GC-MS/MS analysis, $1 \mathrm{~mL}$ of the supernatant is evaporated at $60{ }^{\circ} \mathrm{C}$ under a stream of nitrogen and then reconstituted by $100 \mu \mathrm{l}$ of ethyl acetate. The separation of pesticides was carried out by a liquid chromatography system using a Shimadzu high-pressure binary mixture equipped with a $100 \mathrm{~m}$ long Restek reverse phase chromatographic column and $2.1 \mathrm{~mm}$ internal diameter filled with particles of $3 \mu \mathrm{m}$ in diameter. For GC-MS / MS, the separation of pesticides is performed by a chromatographic column of 5-MS Agilent 30 $\mathrm{m}$ length, $0.25 \mathrm{~mm}$ internal diameter with a polar film of 0.25 microns. To analyse the dithiocabamates (mancozeb, maneb, metiram, zineb...) by screening by Headspace - Gas Chromatography - Mass spectrometry (HSGC-MS) system, $3 \mathrm{ml}$ of $5 \mathrm{~g} / 1$ stannous chloride in $5 \mathrm{~N} \mathrm{HCl}$ are added to $2 \mathrm{~g}$ of vegetables crushed in a $20 \mathrm{~mL}$ flask and then crimped and stirred. The sample is heated for 15 minutes at $100{ }^{\circ} \mathrm{C}$ and then transferred to the headspace sample changer. Dithiocarbamates are quantitatively converted to carbon disulphide $\left(\mathrm{CS}_{2}\right)$ and residue levels of dithiocarbamates are expressed as $\mathrm{mg}$ $\mathrm{CS}_{2} / \mathrm{kg}$ food.

\section{Data analysis}

The modified 24 hours recall method (24 HR) proposed by Gibson and Ferguson (2008) was used to establish the food consumption rate for the vegetables crops. The health risk assessment was done according to the method of US EPA and Seo et al. (2013). 


\section{Quality control}

For quality control, the sample extracts, when dosed, were compared with standards supplemented (calibrators or quality control) at known concentrations and in the matrices to be assayed. All samples were quantified with an extracted range with 4 concentrations covering the range of 0.005 $\mathrm{mg} / \mathrm{kg}$ to $0.250 \mathrm{mg} / \mathrm{kg}$ and a blank.

\section{Health Risk Assessment}

In Togo, studies as regards to health risk assessment of dietary intake of fruits and vegetables are very scarce. The available studies have highlighted misuse of pesticides and their handling, on cash crops (Cocoa, cotton), staple crops (Maize), vegetable crops (eggplant, okra, pepper, cucumber, spinach lettuce...) and their hazard to human health (Mawussi et al., 2009; Adjrah et al., 2013; Gnandi et al., 2008). Data on dietary intake of fruits and vegetables in Togo are not available and the risk assessment of pesticide residues on food based on toxicological evaluation is not addressed. Thus for the evaluation of toxicological risks, a survey on the daily consumption rate per vegetable is made among gardeners and general population selected randomly to establish the food consumption rate for the vegetables crops using the modified 24 hours recall method (24 HR) proposed by Gibson and Ferguson (2008).

In order to reduce bias in the study, surveys were conducted during 10 days consecutively in order to cover all events. Also Importance was given to women because of their role in cooking, difference was made between food eaten raw and cooked because some vegetables eaten raw are totally consumed while for cooked vegetables some parts are thrown when cooked. The weighted average portion estimate (WAPE) for the population is calculated as follows:

\section{WAPEi $=\sum_{1}^{n} F n P U n P p n$}

Where $F_{n}$ is the average portion of a given food commodity in a recipe/volume of water from a source $\mathrm{n}$ (g/pers), $\mathrm{PU}_{\mathrm{n}}$ the probability that the food commodity is used in the given recipe $(\mathrm{PUn}=1$ for water consumption estimation) and $\mathrm{Pp}_{\mathrm{n}}$ the probability of occurrence of the given recipe/use of the water source in the studied population diet.

The risk assessment of pesticide residues in food is based on toxicological evaluation of the single and several compounds, of exposure to multiple pesticide residues in food crops, vegetables, and fruits. The scenario of pesticide residues risk assessment on consumers is based on US EPA guidelines:

- (a) hypothetical body weight of $10 \mathrm{~kg}$ for children and $70 \mathrm{~kg}$ for adults and

- (b) maximum absorption rate of $100 \%$ and bioavailability rate of $100 \%$.

- (c) pesticide residue level, the mean

For each type of exposure, the estimated lifetime exposure dose (Admissible Daily intake), (mg/kg/day) was obtained by multiplying the residual pesticide concentration $(\mathrm{mg} / \mathrm{kg})$ in the food of interest times by the food consumption rate IR (kg/Person/day), and then dividing the product by the body weight $(\mathrm{kg})$.

The hazard indices for adults and children chronic exposure were calculated as ratios between estimated pesticide exposure doses or acceptable daily intake (ADI) and the reference doses ARfD which are considered to be safe levels of exposure over the lifetime.

$\mathrm{HRI}=A D I / A R f D$

When this quotient exceeds the unity ( $>100 \%$ of ARfD or ADI) it indicates a risk.

When more than one residue is present, HRI of pesticides with the common mode of action were summed to account for cumulative toxicity (Donkor et al., 2016).

$\mathrm{HRI}=\sum_{i=1}^{n} H R I$

The health risks of systemic effects associated with pesticide residues in different vegetables are presented in the Table 3. 


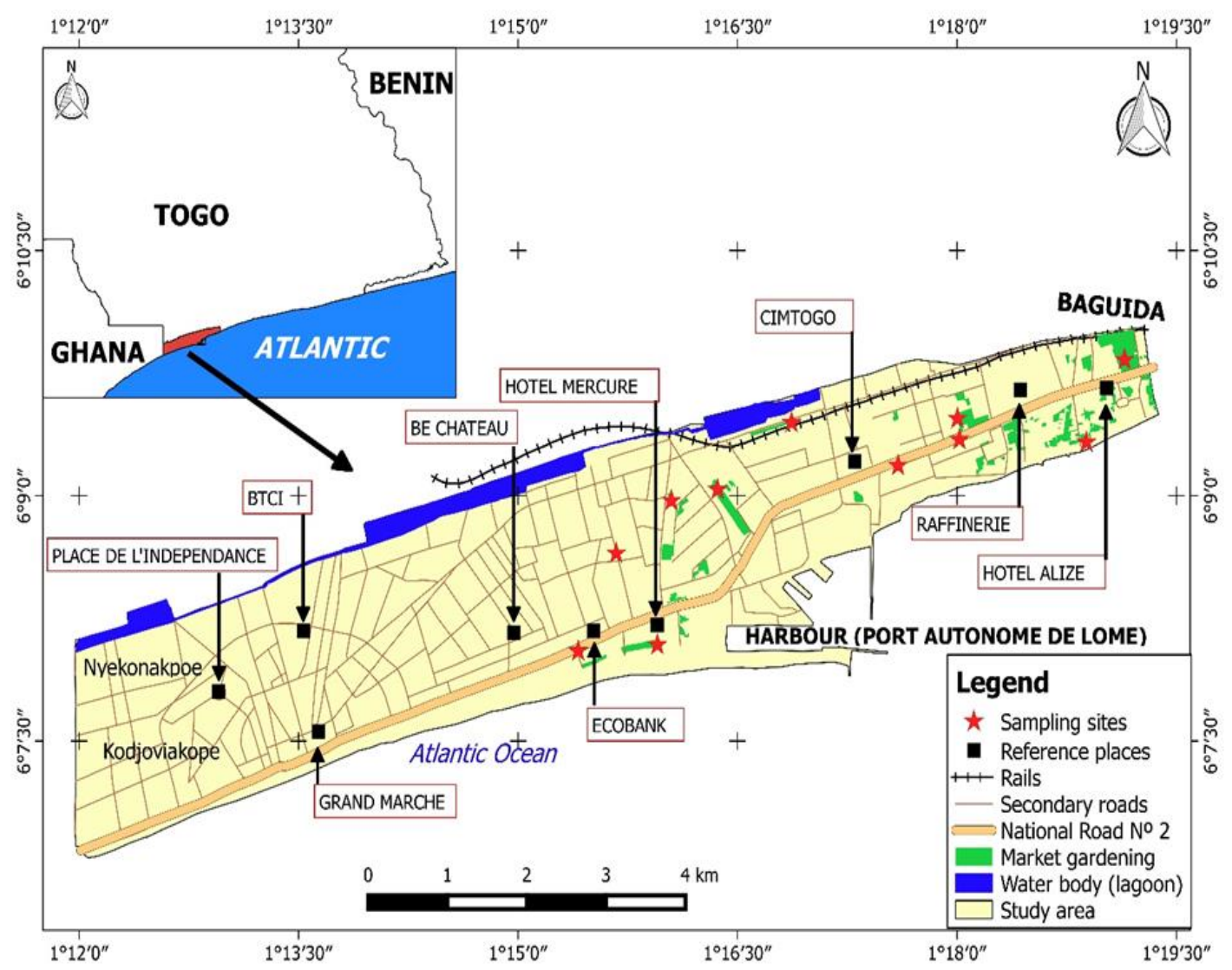

Figure 1: Study zone.

\section{RESULTS}

Table 1 shows the results of the samples analysed. A total of 14 vegetable samples in triplicate (42) were analysed for detection of pesticides using multi pesticide residues method to determine the presence or absence of pesticides in vegetables. This Table 1 shows that all of samples were contaminated by pesticides with the concentration ranging from $0.006 \mathrm{mg} / \mathrm{kg}$ to $7.79 \mathrm{mg} / \mathrm{kg}$.fresh weight. About 33 (78.57\%) samples, have their residues above maximum residues levels (MRLs) and $9(21.43 \%)$ are in the standards of the European Union. Dithiocarbamates were the group frequently detected in vegetable samples and have the highest concentrations of residues in carrot, which exceeded the maximum residue levels. Their concentrations are expressed as $\mathrm{mg}$
$\mathrm{CS}_{2} / \mathrm{kg}$ food and ranged from $0.012 \mathrm{mg} / \mathrm{kg}$ fresh weight to $7.79 \mathrm{mg} / \mathrm{kg}$. This family of pesticides is detected in carrot, spinach, onion, leek and pepper respectively at $7.79 \mathrm{mg} / \mathrm{kg}$, $0.34 \mathrm{mg} / \mathrm{kg}, 0.018 \mathrm{mg} / \mathrm{kg}$, and $0.012 \mathrm{mg} / \mathrm{kg}$. In the spinach, pepper, and cucumber, chlorpyrifos ethyl was detected at 0.445 $\mathrm{mg} / \mathrm{kg}, \quad 0.0032 \mathrm{mg} / \mathrm{kg}$, and $0.239 \mathrm{mg} / \mathrm{kg}$ respectively, from which samples it exceeded the MRLs.

The pesticides cypermethrin $(0.254$ $\mathrm{mg} / \mathrm{kg}), \quad$ chlorothalonil $(0.126 \mathrm{mg} / \mathrm{kg})$, carbendazim $\quad(0.094 \quad \mathrm{mg} / \mathrm{kg}), \quad$ and prothioconazole $(0.04 \mathrm{mg} / \mathrm{kg})$ in pepper, pendimethalin $(0.037 \mathrm{mg} / \mathrm{kg})$ in turnips, were detected at concentrations exceeding the MRL recommended by European Union. In table 1 it was also found that pepper contained 5 residues, leek 4 pesticides, turnip 4 pesticides, 
eggplant 3 pesticides and spinach and lettuce 2 pesticides each other.

The results of figure 2 show that the most commonly detected pesticides with high apparition of residues were dithiocarbamates $(35.71 \%)$, flowed by chlorpyrifos ethyl $(35.71 \%)$, cypermethrin $(21.42 \%), \quad \lambda$ cyhalothrin (14.28\%), imidacloprid (14.28\%) and carbendazim (14.28\%). The pesticides identified belong to 10 families which are neonicotinoids, dithiocarbamates, pyrethroids, organophosphates, benzonitriles, diamides, triazoles, dinitroanilines, Avermectines, Acylamines making them the most available and use in crops protection in Lomé.
This study also shows that, chemical in Class Ia and Class Ib are absent and all chemical products in vegetable crops, are in lower. Who hazards classes: II, III, U (WHO, 2009).

The result of the food consumption rate of vegetables presented in table 2 shows low consumption of vegetables contaminated. This table shows that, vegetables Jew's mallow, eggplant, and okra are frequently consumed by the population.

The cumulative health risk assessment (Table 3), associated with pesticide exposure in vegetables, shows negligible effects on consumers according to the method employed.

Table 1: Pesticide concentrations in vegetable samples (mg/kg).

\begin{tabular}{|c|c|c|c|c|}
\hline $\begin{array}{l}\text { Vegetables } \\
\text { (number samples) }\end{array}$ & Pesticide detected & $\begin{array}{l}\text { Mean } \\
(\mathrm{mg} / \mathrm{kg})\end{array}$ & $\begin{array}{l}\text { MRLs }^{\mathrm{b}} \\
(\mathrm{mg} / \mathrm{kg})\end{array}$ & Chemical families \\
\hline \multirow[t]{2}{*}{ Lettuce (3) } & $\begin{array}{l}\text { Lambda } \\
\text { cyhalothrin }\end{array}$ & 0,03 & 0,5 & Pyrethroids \\
\hline & Chlorepyrifos ethyl & 0,051 & 0,05 & Organophosphates \\
\hline Jew's mallow (3) & Metalaxyl & 0,012 & 0,01 & Acylamines \\
\hline \multirow[t]{3}{*}{ Eggplant (3) } & Acetaprid & 0,012 & 0,02 & Neonicotinoids \\
\hline & Emamectin & 0,005 & 0,2 & Avermectines \\
\hline & Cypermethrin & 0,073 & 0,5 & Pyrethroids \\
\hline Beet (3) & Imidacloprid & 0,016 & 0,5 & Neonicotinoids \\
\hline Carrot (3) & Carbon disulphide & 7,79 & 0,2 & Dithiocarbamates \\
\hline \multirow[t]{2}{*}{ Spinach (3) } & Chlorpyrifos ethyl & 0,445 & 0,02 & Organophosphates \\
\hline & Carbon disulphide & 0,034 & 0,05 & Dithiocarbamates \\
\hline \multirow[t]{4}{*}{ leek (3) } & Cypermethrin & 0,024 & 0,05 & Pyrethroids \\
\hline & Dimethoate & 0,014 & 0,02 & Organophosphates \\
\hline & Carbon disulphide & 0,012 & 0,5 & Dithiocarbamates \\
\hline & lambda cyhalothrin & 0,005 & 0,2 & Pyrethroids \\
\hline \multirow[t]{4}{*}{ Turnip (3) } & Chlorpyrifos ethyl & 0,121 & 0.01 & Organophosphates \\
\hline & Imidacloprid & 0,006 & 0,6 & Neonicotinoïds \\
\hline & Pendimethaline & 0,037 & 0.05 & Dinitroanilines \\
\hline & Prothioconazole & 0,04 & 0,01 & Tiazoles \\
\hline \multirow[t]{4}{*}{ Pepper (3) } & Carbendazime & 0,094 & 0,01 & Benzimidazoles \\
\hline & Chlothalonil & 0,126 & 0,01 & Organochlorine \\
\hline & Chlorpyrifos ethyl & 0,032 & 0,01 & Organophosphates \\
\hline & Cypermethrin & 0,254 & 0,05 & Pyrethroids \\
\hline
\end{tabular}




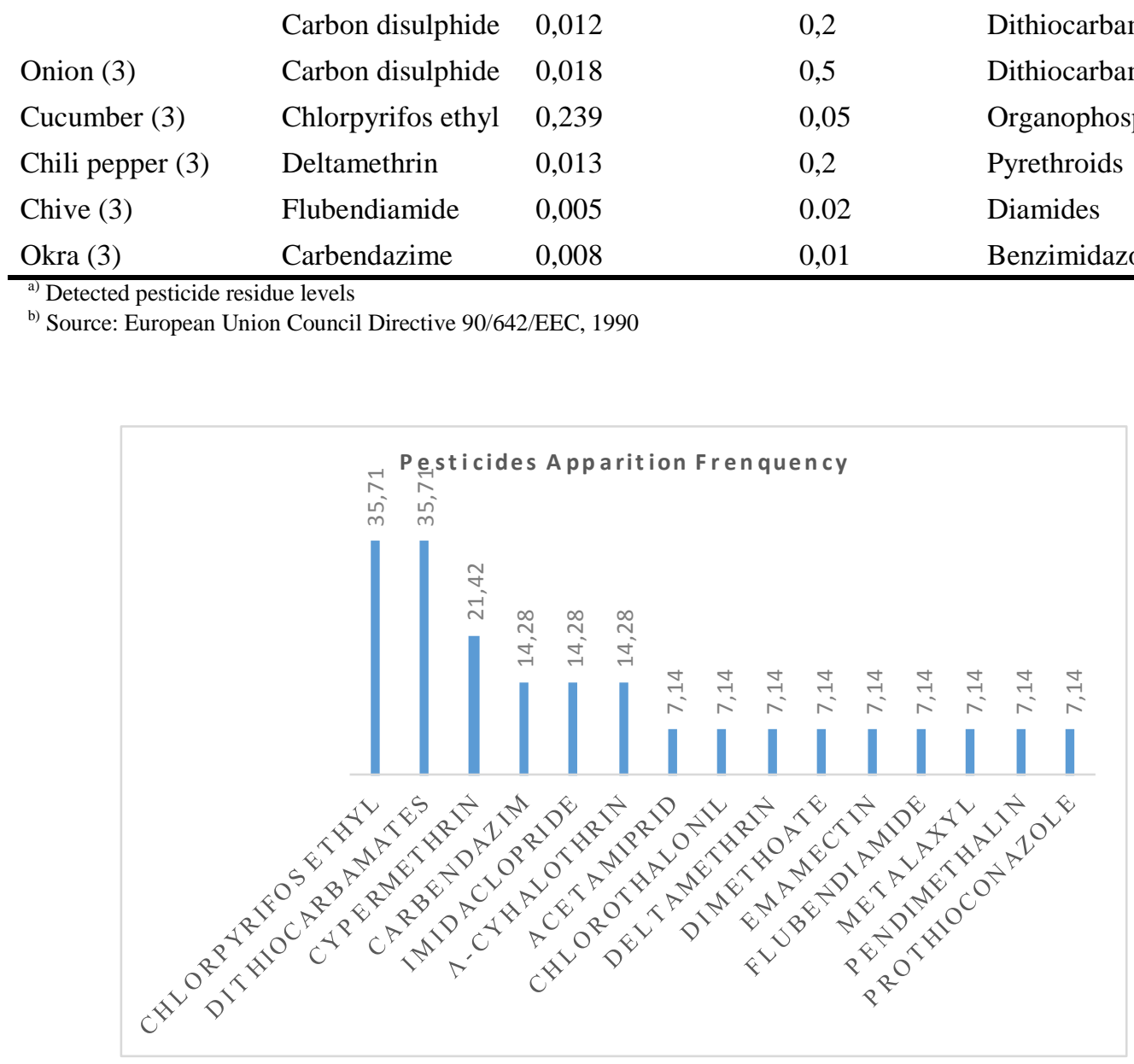

Figure 2: Pesticides apparition frequency in the vegetables samples (\%).

Table 2: Food consumption rate (kg/Person/day).

\begin{tabular}{lclc}
\hline Commodity & Food consumption rate & Commodity & Food consumption rate \\
\hline Lettuce & 0.014 & Turnip & 0.001 \\
Jew's mallow & 0.02 & Pepper & 0.001 \\
Eggplant & 0.052 & Onion & 0.004 \\
Beet & 0.013 & Cucumber & $3.2 \mathrm{E}-04$ \\
Carrot & 0.017 & Chili pepper & 0.002 \\
Spinach & 0.009 & Chive & $8.2 \mathrm{E}-05$ \\
Leek & $4.0 \mathrm{E}-04$ & Okra & 0.113 \\
\hline
\end{tabular}


Table 3: Exposure assessment parameters of pesticides in vegetables ( $\mathrm{mg} / \mathrm{kg} / \mathrm{day})$.

\begin{tabular}{|c|c|c|c|c|}
\hline Commodity & Detected Pesticides & $\mathrm{ADI}^{1}$ & EDI $^{2}$ & $\operatorname{HRI}^{3}(\%)$ \\
\hline \multirow[t]{2}{*}{ Lettuce } & $\lambda$-cyhalothrin & 0.02 & $6.0 \mathrm{E}-06$ & 0.03 \\
\hline & Chlorepyriphos ethyl & 0.01 & $1.02 \mathrm{E}-05$ & 0.10 \\
\hline Jew's mallow & Methanlaxyl & 0.02 & $3.42 \mathrm{E}-06$ & 0.01 \\
\hline \multirow[t]{3}{*}{ Eggplant } & Acetaprid & 0.07 & 8.91E-06 & 0.01 \\
\hline & Emamectin & 0.0005 & $3.71 \mathrm{E}-06$ & 0.74 \\
\hline & Cypermethrin & 0.02 & $5.42 \mathrm{E}-05$ & 0.27 \\
\hline Beet & Imidacloprid & 0.06 & $2.97 \mathrm{E}-06$ & $4.95 \mathrm{E}-03$ \\
\hline Carrot & Dithiocarbamates & 0.03 & $1.89 \mathrm{E}-3$ & 6.30 \\
\hline \multirow[t]{2}{*}{ Spinach } & Chlorpyriphos ethyl & 0.01 & $5.72 \mathrm{E}-05$ & 0.57 \\
\hline & Dithiocarbamates & 0.01 & 4.37E-06 & 0.04 \\
\hline \multirow[t]{4}{*}{ leek } & Cypermethrin & 0,02 & $1.37 \mathrm{E}-07$ & $6.85 \mathrm{E}-04$ \\
\hline & Dimethoate & 0.01 & 8.0E-08 & 8.0E-04 \\
\hline & Dithiocarbamates & 0.01 & $6.85 \mathrm{E}-08$ & $6.85 \mathrm{E}-04$ \\
\hline & $\lambda$-cyhalothrin & 0.02 & $2.85 \mathrm{E}-08$ & $1.42 \mathrm{E}-04$ \\
\hline \multirow[t]{4}{*}{ Turnip } & Chlorpyriphos ethyl & 0.01 & $1.72 \mathrm{E}-06$ & 0.01 \\
\hline & Imidacloprid & 0.06 & $8.57 \mathrm{E}-08$ & $1.42 \mathrm{E}-04$ \\
\hline & pendimethalin & 0.01 & $5.28 \mathrm{E}-07$ & $5.28 \mathrm{E}-03$ \\
\hline & Prothioconazole & 0.01 & $5.71 \mathrm{E}-07$ & $5.71 \mathrm{E}-3$ \\
\hline \multirow[t]{5}{*}{ Pepper } & Carbendazim & 0.01 & $1.34 \mathrm{E}-06$ & 0.01 \\
\hline & Chlorothalonil & 0.02 & $1.8 \mathrm{E}-06$ & $9.0 \mathrm{E}-03$ \\
\hline & Chlorpyriphos ethyl & 0.01 & $4.57 \mathrm{E}-07$ & $4.57 \mathrm{E}-03$ \\
\hline & Cypermethrin & 0.02 & $3.62 \mathrm{E}-06$ & 0,01 \\
\hline & Dithiocarbamates & 0.01 & $1.71 \mathrm{E}-07$ & $1.71 \mathrm{E}-03$ \\
\hline Onion & Dithiocarbamates & 0.01 & $1.02 \mathrm{E}-06$ & 0.01 \\
\hline Cucumber & Chlorpyriphos ethyl & 0.01 & $1.09 \mathrm{E}-06$ & 0.01 \\
\hline Chili pepper & Deltamethrin & 0.01 & $3.71 \mathrm{E}-07$ & $3.71 \mathrm{E}-03$ \\
\hline Chive & Flubendiamide & 0.02 & $5.85 \mathrm{E}-09$ & $2.92 \mathrm{E}-05$ \\
\hline Okra & Carbendazim & 0.01 & $1.29 \mathrm{E}-05$ & 0,12 \\
\hline
\end{tabular}




\section{DISCUSSION}

All the studied vegetables were contaminated with pesticides authorised by the relevant department (Table1). The high concentration of dithiocarbates pesticides can be explained by the non-respect of the recommended dose and to its recent use. Dithiocarbamates can act in toxic synergy with other pollutants, including lead in the foetus, crossing the placental barrier (William, 2010). They decompose slowly when exposed to heat and light, but eventually producing toxic metabolites that are harmful to the body (Tammy et Robert, 2010). The chlorpyrifos ethyl and in general organophosphates, acute toxicity is primarily caused by the inhibition of cholinesterase. Their toxic effects are manifested by muscarinic and nicotinic overstimulation as well as reduced activity of both erythrocyte acetylcholinesterase and plasma butyrylcholinesterases (Thabet et al., 2009). Although vegetables were washed with tap water to simulate how they are consumed by the population, pesticide residues, remain at high or low concentrations. This situation leads every year by the intoxication of populations. Studies conducted by ANCETogo in 2003 indicated that more than 500 cases of intoxication related to the use of endosulfan were recorded annually by the Toxicology Division of Lomé-Tokoin Public Hospital.

The apparition of more than one pesticide residues in many vegetables can be explained by the multiple combination of different groups of pesticides and their simultaneous spray on vegetables in order to protect their crops and have good yields, thus showing the lack of knowledge regarding Good Agricultural Practices (GAP) (Lehmann et al., 2017). These results are similar to those conducted in Pakistan by Yawar et al. (2011), and by Lehmann et al. (2017) in Burkina Faso on crops. According to world health organisation (Who, 2009), many formulators seek to improve their products by making mixtures of active ingredients, while some change formulations or proportions of active products without changing the name of the proprietary product. The result is that utilisation of these chemical substances leads to the simultaneous existence of several amounts of pesticides in the same vegetable which becomes a great health hazard.

The food consumption rates (Table 2) of contaminated vegetables are low but health effects for consumers can be considered with the apparition of multiple pesticides residues in vegetables and when raw vegetables consumption is important without any great precautions. In Lomé and in general in subsaharian countries, overuse and random combination of different groups of pesticides are a serious concerns (Adjrah et al. 2013 ; Kanda et al. 2013 ; Yawar et al. 2011) and this can lead to the development of resistances within crop pests.

Pesticide residues and their numbers vary from one vegetable to another and from one sampling point to another and this practice is common to subsaharan countries. This does not allow to correlate and understand the accumulation of pesticides between plants species and sampled areas because some pesticide residues such as organochlorines are persistent and can remain in contaminated soils and continue to move from soil to vegetables (Hellar-Kihampa, 2011). The pesticide residue levels could be explained by lack of awareness and low educational levels $(31,2 \%$ illiterates $)$ of farmers about application doses, and methods of application. The negligence or nonavailability of proper guidance about pesticide application may be another reason, which may lead to contamination of vegetables with pesticide residues.

The single and cumulative health risk assessment (Table 3), associated with pesticides exposure in vegetables, showed a negligible effects on consumers, but pesticides 
exposure by vegetables consumption, can be considered as a concern due to the consumption of raw foods such as carrots, lettuce, cucumbers if they are badly washed.

The survey of pesticides handling, use, and educational level of market gardeners, showed that, most of them are illiterate $(31.2 \%)$, or have low educational levels $(35 \%)$. Only $5 \%$ of farmers have received training on pesticides use. This is a great concern because the majority of imported pesticides notices are in English. Market gardeners learn from their peers and vendors about the use of pesticides and all of them have recognised mixing more than two pesticides to effectively combat diseases and plant pests. This is a very harmful practice both for the farmers and the environment. The majority of growers do not respect the waiting period for the harvest exposing consumers to health risks. In the last decades, pesticides in class Ia and $\mathrm{Ib}$, were banned due to their high toxicity on human beings and the environment all over the world and in Togo, making them less available. This can explain their absence from the vegetables studied. This confirm the reports of the World Health Organisation, on the ban of pesticides of high toxicity use (WHO, 2009), and the third International Conference on Chemicals Management in Nairobi, in September 2012, where over than 60 countries and other participating organisations called for the Conference to support the development of a list of Highly Hazardous Pesticides (HHPs), a progressive ban of HHPs, and their substitution with safer alternatives (PAN, 2018).

\section{Conclusion}

The results of this study indicate that $78,57 \%$ of samples were contaminated with pesticide residues above European Union MRL. However health risks indexes in studied conditions, showed that these residues levels are not harmful to health. Farmers do not follow proper precautions and policies on pesticides use with regard to the use of pesticides in appropriate dose. Although the results show a negligible risk associated with exposure via vegetables consumption, there is a need for high precautions with the possible total exposure to these pesticides. Thus the abuse use of pesticides on vegetables has enhanced potential risk of contamination of environment and long-term effect on society. Therefore political makers should play their role effectively to protect the population and the environment. Due to increasing trend in pesticide use, continuous monitoring of pesticide residues in vegetables is recommended in order to develop the baseline data on which future strategy could be implemented for the protection of the consumers and the environment. Future studies should evaluate pesticide residues in the blood samples of market gardeners to determine their effects on their health.

\section{COMPETING INTERESTS}

The authors declare that they have no competing interests.

\section{AUTHORS' CONTRIBUTIONS}

This study was possible in the direction of $\mathrm{KG}$, EEC, respectively director, and codirector. Laboratory analyses were done in collaboration with $\mathrm{CM}$ and $\mathrm{J}-\mathrm{CY}$, technical managers of the laboratory of analysis of the University of Limoges which allowed the extraction and dosage of pesticide residues and the writing of experimental protocols. The collection, selection and conditioning of the samples were done in collaboration with GT and KO.

\section{ACKNOWLEDGMENTS}

Authors would also thank the Directors of Laboratoire de Toxicologie et d'Hygiène Appliquée of the University of Bordeaux and the Department of Pharmacology, Toxicology of the University hospital of Limoges, France, 
for the importance and the quality of this study.

\section{REFERENCES}

Adjrah Y, Dovlo A, Karou SD, EkluGadegbeku K, Agbonon A, de Souza C, Gbeassor M. 2013. Survey of pesticide application of vegetables in the Littoral area of Togo. Ann Agric Environ Med., 20(4): 715-720.

https://www.ncbi.nlm.nih.gov/pubmed/2 4364441

ANCE Togo. 2007 : Etude de la situation du Togo en matière de POP.

Agricultural Statistics of Pakistan. 2003-2004. MINFAL: Ministry of Food, Agriculture and Livestock.

Biego HMG, Coulibaly A, Koffi MK, Chatire OK, Kouadio LP. 2009. Niveaux de résidus de pesticides organochlorés dans les produits du cacao en Côte d'Ivoire. Int. J. Biol. Chem. Sci., 3(2): 297-303. http://ajol.info/index.php/ijbcs

Gbaguidi MAN, Soclo HH, Issa YM, Fayomi B, Dognon R, Agagbe A, Bonou C, Youssao A, Dovonou LF, Sanni A. 2011. Évaluation quantitative des résidus de pyréthrinoïdes, d'aminophosphate et de triazines en zones de production de coton au Bénin par la méthode ELISA en phase liquide : cas des eaux de la rivière Agbado. Int. J. Biol. Chem. Sci., 5(4): 1476-1490.

http://ajol.info/index.php/ijbcs

90/642/EEC. 1990. Council Directive on 27

November of maximum levels of pesticide residues in and on certain products of plant origin, including fruit and vegetables. https://www.fsai.ie/uploadedFiles/Legisl ation/Food_Legisation_Links/Pesticides _Residues_in_food/Council_Directive_9 0_642_EEC.pdf

Donkor A, Osei-Fosu P, Dubey B, KingsfordAdaboh R, Ziwu C, Asante I. 2016. Pesticide residues in fruits and vegetables in Ghana: a review. Environ Sci Pollut Res Int., 23(19): 18966-87. http://www.orgdoi/10.1007/s11356-0167317-6.

Gibson RS, Ferguson EL. 2008. An Interactive 24-hour Recall of Assessing the Adequacy of Iron and Zinc Intakes in Developing Countries. HarvestPlus Technical Monograph 8. Washington, DC and Cali: International Food Policy Research Institute (IFPRI) and International Centre for Tropical Agriculture (CIAT).

Gnandi K, Tozo K, Edorh AP, Abi H, Agbéko K, Amouzouvi K, Baba G, Tchangbédji G, Killi K, Bouchet P, Akpagana K. 2008. Bioaccumulation de certains éléments métalliques dans les produits maraîchers cultivés sur les sols urbains le long de l'autoroute Lomé Aného, Sud Togo. Acta Botanica Gallica, 155: 3 : 415-426.

DOI: http://dx.doi.org/10.1080/12538078.2008 .10516121

Guler GO, Cakmak YS, Dagli Z, Aktumsek A, Ozparlak H. 2010. Organo-chlorine pesticide residues in wheat from Konya region, Turkey. Food Chem. Toxicol., 48: 1218-1221.

Hellar-Kihampa H. 2011. The organo-chlorine pesticide residues in soil from sugarcane plantations in Kilimanjaro, Tanzania. Int. J. Biol. Chem. Sci., 5(1): 247-257. http://ajol.info/index.php/ijbcs

HSDB, National Library of Medicine Hazardous Substances Data Bank. 2018 a. Carbendazim (CASRN: 10605-217). 〈http://toxnet.nlm.nih.gov/cgibin/sis/sear ch2/r?Dbs+hsdb:@term+@DOCNO+65 81)

Iqbal MF, Maqbool U, Perveez I, Farooq M, Asi MR. 2009. Monitoring of insecticide residues in brinjal collected from the market of noshera virkan, Pakistan. $J$. Anim. Plant Sci., 19: 90-93. 
Jean-Pierre A, Pascal K. 2009. Difficultés analytiques de la caractérisation des pesticides dans le sang. Ann Toxicol Anal., 21(3): 131-141. https://doi.org/10.1051/ata/2009041

Joint FAO/WHO Meeting on Pesticide Residues in food report 2010, 2011, 2012, 2013, 2014, 2015, 2016, 2017. http://www.fao.org/agriculture/crops/the matic-sitemap/theme/pests/jmpr/jmprrep/en/

Kanda M, Djaneye-Boundjou G, Wala K, Gnandi K, Batawila K, Sanni A, Akpagana K. 2013. Application des pesticides en agriculture maraichère au Togo. VertigO - la revue électronique en sciences de l'environnement, 13(1). http://dx.doi.org/10.4000/vertigo.13456

Khizar H, Muhammad A, Umair A, Mushtaq AS. 2010. Determination of pesticide residues in blood samples of villagers involved in pesticide application at District Vehari (Punjab), Pakistan. Afr. J. Environ. Sci. Technol., 4(10): 666684.

Koes uk wiwat U, Lehotay SJ, Miao S, Leepipatpiboon N. 2010. High throughput analysis of 150 pesticides in fruits and vegetables using QuEChERS and low-pressure gas chromatographytime-of-flight mass spectrometry, Journal of Chromatography A., 1217(43): 6692-6703.

Kokou E, Kanda M, Akpavi S, Wala K, Batawila K, Akpagana K. 2014. Appariton d'un commerce informel de produits phytosanitaires au sud - ouest du Togo. European Scientific Journal, 10(6).

Lehmann E, Nuria T, Marius K, Yacouba K, Luiz F. 2017. Dietary risk assessment of pesticides from vegetables and drinking water in gardening areas in Burkina Faso. Science of the Total Environment (601-602):

1208-1216. https://doi.org/10.1016/j.scitotenv.2017. 05.285 .

Mahob RJ, Ndoumbè-Nkeng M, Ten Hoopen GM, Dibog L, Nyassé S, Rutherford M, Mbenoun M, Babin R, Amang J, Mbang A, Yede C, Bilong Bilong F. 2014. Pesticides use in cocoa sector in Cameroon: characterisation of supply source, nature of active ingredients, fashion and reasons for their utilisation. Int. J. Biol. Chem. Sci., 8(5): 1976-1989. http://dx.doi.org/10.4314/ijbcs.v8i5.3

Mawussi G, Sanda K, Merlina G, Pinelli E. 2009. Assessment of average exposure to organochlorine pesticides in southern Togo from water, maize (Zea mays) and cowpea (Vigna unguiculata). Food Addit Contam., 26: 348-354.

PAN International List of Highly Hazardous Pesticides. 2018. PAN Germany, Nernstweg 32, 22765 Hamburg, Germany.

Regulations of the Parliament and Council of the European Union (EU) Committee on pesticides in or on food and feed of plant and animal origin on line: EUR-Lex 52017DC0130 - EN - EUR-Lex - Europa EU.

Report of the Joint Meeting of the FAO Panel of Experts on Pesticide Residues in Food and the Environment and the WHO Core Assessment Group on Pesticide Residues, 2010_2015.

Sánchez-Guerra M, Pérez-Herrera N, Quintanilla-Vega $\quad$ B. 2011. Organophosphorous pesticides research in Mexico: epidemiological and experimental approaches. Toxicol Mech Methods, 21: 681—691.

Seo Y, Cho T, Hong C, Kim M, Cho S, Park W, Hwang I, Kim M. 2013. Monitoring and Risk Assessment of Pesticide Residues in Commercially Dried Vegetables. Prev. Nutr. Food Sci., 18(2): 145-149. 
http://dx.doi.org/10.3746/pnf.2013.18.2. 145

Steeve HT, Pascal R, Guy L. 2013. Neurotoxicité des pesticides. Quel impact sur les maladies neurodégénératives ? $\mathrm{m} / \mathrm{s}, \mathbf{2 9}(3)$. DOI : http://dx.doi.org/10.1051/medsci/201329 3013.

Tammy ES, Robert JK. 2010. Pesticides as Disruptive Chemicals of the Endocrine System in Handbook of Pesticides Toxicology (3rd Edn). Academic Press.

Thabet H, Brahmi N, Kouraïchi N, Elghord H, Amamoub M. 2009. Intoxication par les pesticides organophosphorés : nouveaux concepts. Réanimation, 18: 633-639. DOI :

http://dx.doi.org/10.1016/j.reaurg.2009.0 5.006

The WHO Recommended classification of pesticides by hazard and guidelines to classification. 2009. WHO, 1211 Geneva
27, Switzerland, or from WHO Regional Offices, PP545-551.

Yawar Latif S, Sherazi TH, Bhanger MI. 2011. Assessment of pesticide residues in commonly used vegetables in Hyderabad, Pakistan. Ecotoxicol Environ Saf., 74(8): 2299-303. DOI: 10.1016/j.ecoenv.2011.07.030.

Yazgan MS, Tanik A. 2005. A new approach for calculating the relative risk level of pesticides. Environ Int., 31: 687-692.

William S. 2010. Neurotoxicology of Pesticides, in Hayes' Handbook of Pesticide Toxicology (Third Edition), Krieger R (ed). Academic Press; 791.

Wilson, Clevo. 2001. Why farmers continue to use pesticides despite environmental, health and sustainability costs. Ecological Economics, 39: 449-462. DOI: http://dx.doi.org/10.1016/S09218009(01)00238-5. 